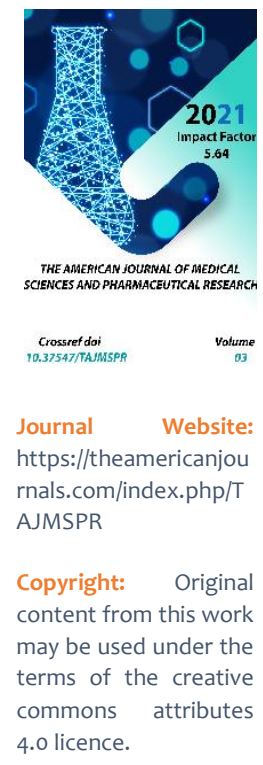

\title{
Morphological Characteristics Of The Kidney In Chronic Alcoholism
}

Hamrayev Izzat Sayfullaevich

Surgeon, The Department Of General Surgery, Republican Emergency Center, Bukhara Branch, Uzbekistan

\section{ABSTRACT}

This research aimed to study the nature of pathomorphological changes in the kidney in chronic alcoholism in rats. In the present study, we have studied experimentally the nature of pathomorphological changes in the kidneys in chronic alcoholism in rats. The longer the intoxication is, the more the kidneys are damaged and homeostatic shifts are more pronounced in young animals. In an experiment on rats, it was found that taking ethanol orally has a short-term effect on kidney tissue and affects water-salt metabolism. Histologically, there are foci of acute inflammation of nephrocytes, spasm of small arterioles, and on the 15th day, atrophic changes in the renal parenchyma. Long-term alcohol intoxication (AIM) leads to persistent morphological disorders of the nephron, which are manifested in changes in the shape and size of the glomerulus, partial sclerosis of loops, vacuolar dystrophy of endothelial cells and partial vacuolar dystrophy of the tubular epithelium, especially the distal part.

\section{KEYWORDS}

Chronic Alcoholism, Rats, Kidney, Experiment.

\section{INTRODUCTION}

Alcoholism, like no other disease, causes a complex of negative social consequences. These consequences are determined by the toxic effect of alcohol, its effect on the physiological, psychosomatic, and behavioural

reactions of a person, on the one hand, and pathogenetic patterns of chronic alcohol intoxication, on the other. Its solution is entrusted to drug addiction doctors in practical health care, whose efforts aim to suppress 
mental and physical dependence on alcohol. At the same time, little attention is paid to the defeat of internal organs. The only exceptions are alcoholic cardiomyopathy and liver damage in alcoholism, the pathogenesis and morphogenesis of which have been intensively analyzed, especially in recent years $[1,17-14,17-$ 21]. Kidney pathology has been studied to a lesser extent. However, the diseases of the excretory system organs occupy the central place in the structure of the overall morbidity of alcohol abusers [22,23,24]. Chronic inflammatory diseases of the excretory system organs account for about $14 \%$ of the overall structure of morbidity; among the causes of death, they occupy the 4th place after cardiovascular, oncological diseases, and injuries. [2,4,5,21]. Many researchers believe that in the pathology of the kidneys in patients with alcoholism, the leading place belongs to chronic nonspecific diseases [9-14,17-19]. Alcohol mortality is not limited only to alcohol poisoning and death from violent causes (murder, suicide); it includes a significant percentage of deaths from somatic pathology associated with alcohol consumption $[20,25]$. In addition, studies carried out in this direction, in the dynamics of the formation of chronic alcohol intoxication, allow us to determine that a single use of a moderate dose of ethanol in the development of renal failure is of no minor importance since the works are devoted to determining the amount of ethanol introduced or the duration of its use as risk factors, to reduce the anti-infectious resistance of the kidneys. However, there is still a clear concept about the state of various links of anti-infective resistance of the kidneys during alcohol intoxication. The organs of the excretory system as a whole represent a kind of target in chronic alcohol abuse.

\section{MATERIALS AND METHODS}

The study was carried out on 25 white outbreed rats weighing 180-210 g. The animals were divided into two groups; in 10 rats, they were reproduced inside the gastric administration of water, served as a control. Animals of series 2 were injected intragastrically with ethanol at a $10 \mathrm{mg} / \mathrm{kg}$ body weight dose. The animals were sacrificed $3,7,15,30$ (days) after exposure to ethanol and were removed from the experiment at 3 months of age by instant decapitation of the animals under ether anaesthesia. According to generally accepted rules, kidney tissue extracted from the abdominal cavity was fixed in $10 \%$ formalin solution and embedded in paraffin. Then, histological sections with a thickness of 6-7 $\mu \mathrm{m}$ were prepared, which were stained with hematoxylin and eosin. Morphological studies of kidney tissue were studied under a Leyka microscope. The experiments on laboratory animals were carried out following the Declaration of the International Medical Association, adopted in Helsinki in 1964 and completed in 1975, 1983, 1989, 1996, 2000, 2002, 2004, 2008, and 2013.

\section{RESULTS AND DISCUSSION}

Microscopic examination of the kidneys in the early stages in the parenchyma revealed oedema, dyscirculatory disorder; the cellular composition revealed the disintegration of lymphocytes in the form of karyopycnosis. In an experiment on rats, it was found that taking ethanol orally has a short-term effect on kidney tissue and affects water-salt metabolism. The filtration and reabsorption function of the kidneys and desquamation of the epithelium of the renal tubules were also impaired. Histological foci of acute inflammation of nephrocytes, spasm of small arteries are 
noted, and on the 15th day in the renal parenchyma, atrophic changes were revealed the following changes.

On the 30th day after the introduction of ethanol, pronounced dysfunction of the convoluted tubules of the kidneys and immune cells was noted. We also identified lymphoidcell infiltration of the stroma with symptoms of fibrosis and sclerosis in the kidney tissue and microcirculation disorders in the kidneys. Signs of chronic pyelonephritis of varying degrees were found in the discharged tubules of the kidneys; there was also vacuolar degeneration of the epithelium and an expression of impairment. In an experiment on animal models, it was found that excessive consumption of ethanol led to the dysfunction of the kidney tissue, which is the cause of chronic renal failure. The background of ethanol intake, filtration, reabsorption, homeostasis, and renal necrosis was impaired. Chronic alcoholization in rats led to pronounced disturbances in water-salt balance, which is characterized by a change in the background indices of renal function and significant changes in the concentration of monovalent cations in plasma. These homeostatic shifts were more pronounced in young animals. Water and salt stress tests reveal latent disturbances in water-salt metabolism in alcoholized rats. Under conditions of 8 water loads, this is characterized by a more inert diuretic reaction, with increased excretion of monovalent cations, and when using a salt load, a delay in sodium excretion and increased potassium excretion. Long-term alcohol intoxication (AIM) leads to persistent morphological disorders of the nephroma, which are expressed in changes in the shape and size of the glomerulus, partial sclerosis of loops, vacuolar degeneration of endothelial cells, and partial vacuolar degeneration of the tubular epithelium, especially the distal part. Significant volumetric water-salt loads cause an increase in the degree of damage in rats with AIM.

\section{CONCLUSION}

Thus, chronic alcoholization in rats leads to pronounced disturbances in the water-salt balance, which is characterized by a change in the background indices of renal function and significant changes in the concentration of monovalent cations in plasma. These homeostatic shifts are more pronounced in young animals, and the longer the intoxication is, the more the kidney is damaged.

\section{REFERENCES}

1. Avdeeva T.G. (1994). The influence of mother's alcoholism on the state of health of the newborn. Paediatrics. P. 57-58.

2. Anokhina, I. P., Vertinskaia, A. G., Vekshina, N. L., Nebarakova, T. P., Ovchinnikov, I. V., Druzhina, E. V., \& Ovchinnikova, O. I. (1999). Hereditary alcoholism: some neurochemical and genetic mechanisms. Vestnik Rossiiskoi akademii meditsinskikh nauk, (6), 4347.

3. Apanova O.I., Shelekhin A.A. (2003). Community-acquired pneumonia with the addition of nosocomial infection in persons with chronic alcohol intoxication. News of Science and Technology, Med. Issue Alcoholic disease. P.1-3.

4. Anokhina, I. P., Vekshina, N. L., \& Veretinskaia, A. G. (1997). Central mechanisms of predisposition to psychoactive substance dependence. 
Zhurnal nevrologii i psikhiatrii imeni SS Korsakova, 97(12), 83-84.

5. E.N. Akhmadeeva, E.K. Alekhin, N.R. Khusamova (1996). Fetal alcohol syndrome. Healthcare of Bashkortostan. No. 2-3. pp.46-51.

6. Abdrashidov A.Kh. (1984). Ethanol consumption by rats under conditions of free choice and when giving ethanol solutions as the only source of liquid. Biological bases of alcoholism. Medicine, P. 197-199.

7. Balika Yu.D., Kartashova V.E., Skosyreva A.M. (1982). The impact of alcohol intoxication of pregnant rats on the hematopoietic system of their offspring. Obstetrics and gynecology. №. 9. P. 56-57.

8. Ganapolsky V.P. (2003). The system of opioids and stress hormones in severe mechanical trauma and ethanol intoxication. Diss. Cand. Honey. Sciences. SPb, P. 108.

9. Kazarnovskaya M.Jl, Vasilos A.F, Dmitrienko V.D. (1976). Mutagenic effect of ethyl alcohol on human cell culture. 1st All-Union. Congress of forensic doctors. Abstracts. Report Kyiv, P. 594-595.

10. Kampov-Polevoy A.B, Zhukov V.N. (1979). Study of the baseline alcohol requirement in a laboratory rat population. Dep. IN VINITA. №. 82779.

11. Beatty M. (1997). Alcoholic in the family or overcoming addiction. Per. from English. P. - 331.

12. Voloshin V.M. (2002). State prospects of development of children's psychiatric service in Russia. Social and Clinical Psychiatry,T. 12. Issue. 2.- P.5-9.

13. Garmash I.V., Ryabova A.V., Ezhova L.G. (2003). Severe pneumonia in a patient with alcoholic liver cirrhosis, cytopenia, and disseminated intravascular coagulation (possibilities of modern therapy). News of Science and Technology. Honey series. Issue Alcoholic disease .VINITI, №. 6. P.1-3.

14. V.A. Guryeva, T.B. Dmitrieva, E.V. Makushkin, V. Ya. Gindikin. (2007). Clinical and forensic adolescent psychiatry. Medical Information Agency,P. 488.

15. Emelyantseva TA (2000). The role of a family with alcoholic problems in forming deviant behavior in adolescents. Works of young scientists. - Minsk, P. 142-144.

16. Emelyantseva T.A. (2001). Results and perspectives of psychotherapeutic work on primary prevention of alcohol and drug addiction among adolescents. Minsk, P.210-217.

17. Mirakyan L.A. (1988). Morphological studies of the mucous membrane of the upper respiratory tract in chronic alcohol intoxication in an experiment on animals. Zh. Ear, nose, throat diseases. №. 3. From 28-30.

18. Moiseev B.C. (1996). Markers of alcoholic illness. New honey. jou. №. 4. - P. 24-27.

19. Naydenova N.G. Gordeev M.N. (2002). Alcoholism and pathology of the respiratory system. Narcology, P.23-26.

20. Nalichko NN (1990). Aspiration pneumonia against the background of alcoholism. Clinical. Medicine. №. 4.P.85-87.

21. Hovers L.Ya., Ovchinnikov Yu.M., Drozdov E.D., Kudryashova N.D. (1986). The state of ENT organs in patients with chronic alcoholism. 
Vestnik Otoloroningologii. №. 3.P.71-

73.

22. Arnold, R., Avants, S. K., Margolin, A., \& Marcotte, D. (2002). Patient attitudes concerning the inclusion of spirituality into addiction treatment. Journal of substance abuse treatment, 23(4), 319326.

23. Burke, R. J., Burgess, Z., \& Oberklaid, F. (2003). Workaholism and divorce among Australian psychologists. Psychological reports, 93(1), 91-92.

24. Christodoulou, G. N., Margariti, M., Kontaxakis, V. P., \& Christodoulou, N. G. (2009). The delusional misidentification syndromes: strange, fascinating, and instructive. Current psychiatry reports, 11(3), 185-189.

25. Coleman-Kennedy, C., \& Pendley, A. (2002). Assessment and diagnosis of sexual addiction. Journal of the American Psychiatric Nurses Association, 8(5), 143-151. 